\title{
Mit wspólnotowości jako podstawa interakcji z internetowymi interfejsami
}

Justyna Skrzypnik | Wydział Filologiczny, Uniwersytet Śląski w Katowicach

Słowa kluczowe: komunikacja w sieci

Web 2.0,

media

społecznościowe wspólnotowośc w sieci, słowo w siec obraz w sieci communication in Web 2.0 social media community it the Internet word in the Internet, image in the Internet

\section{Streszczenie}

Rozwój mediów interpretować można jako historię uzewnętrzniania procesów kognitywnych oraz zapośredniczania kontaktu człowieka ze światem, a co za tym idzie - oddzielania go od rzeczywistości. Już od czasów wynalezienia pisma w historię rozwoju mediów wpisane były nieobecność, dystans i osamotnienie. Nowe media (i nowe nowe media), ufundowane na pojęciach interaktywności i uczestnictwa, na pozór zmierzają w odwrotnym kierunku. Społecznościowość i wspólnotowość zdają się być traktowane jako podstawy nowomedialnych doświadczeń użytkowników Web 2.0. „Kultura dzielenia się, udostępniania” czy - jak chce chociażby Mark Zuckerberg - „zmediatyzowanej wymiany darów" to tylko niektóre z pojęć wskazujących na przekonanie o zwrocie w kierunku wspólnotowości w nowych nowych mediach. Pojęcie kolektywności jawi się w tym kontekście jako słowo klucz do interpretacji warunkowanej przez nie kultury. Internetowe algorytmy - PageRank, TrustRank czy EdgeRank - warunkujące selekcję treści w sieci, bazują na przekonaniu, iż ich podstawą nie jest widoczność dla botów, lecz kolektywne uwierzytelnianie treści. W ten sposób konstytuuje się fasadowy, zmityzowany obraz komunikacji Web 2.0, która, z jednej strony, wydaje się implikować powstawanie cyberwspólnot, z drugiej zaś - okazuje się być obszarem pogłębiającej się alienacji.

\section{Community myth as a basis for human's interaction with web interfaces Summary}

The history of media development can be interpreted as a process of externalizing cognitive processes and mediating contact between human and the world, and thus separating it from reality. Since the time of the invention (of writing), such categories as: absence, distance, solitude were embedded in the history of media development. New media (and new new media), founded on the idea of interactivity and participation, seem to go in the opposite direction. The community seem to be seen as the basis of user's web 2.0 experience. The culture of sharing or exchanging gifts are just some of the ideas, which evidences belief in community in the new media. The concept of collectivity appears in this context as the key word for interpretation conditioned by 
the new media culture. Internet algorithms - PageRank, TrustRank, and EdgeRank - determine the content of the network, are based on the belief that their basis is not visibility for bots but collective authentication of content. This is the way to create mythical image of communication in Web 2.0, which seem to implicate the formation of cybercommunities, but on the other hand - proves that communication in Web 2.0 is an area of increasing alienation.

\section{Wstęp}

Internetowe platformy komunikacyjne, takie jak Facebook, Instagram, Twitter, YouTube czy Google, zarówno w społecznym przekonaniu, jak i medioznawczej refleksji uznawane są za media o społecznościowym charakterze i wspólnototwórczym potencjale (Castells 2013: 219-224). Komunikacja Web 2.0 analizowana jest często w odniesieniu do kultury uczestnictwa (Szpunar 2010: 261) rozumianej jako platforma współtworzenia, dzielenia się bądź udostępniania treści. Poza modelem kreacji/produkcji treści oraz ich dystrybucji podstawą takiego rozumienia mediów Web 2.0 mogą być uwarunkowania przekazu, wynikające z samej natury konkretnego medium oraz charakteru przekazywanych za jego pośrednictwem komunikatów. Przyjęcie antropologiczno-medialnej perspektywy pociąga za sobą konieczność redefinicji usieciowionej wspólnotowości i pozwala wysnuć hipotezę o jej fasadowym i mitotwórczym charakterze.

\section{Wspólnototwórczy potencjał paradygmatów oralności i piśmienności w komunikacji}

Kontekst medialno-technologiczny danej kultury determinuje sposób, w jaki człowiek postrzega i definiuje rzeczywistość oraz w jaki umiejscawia siebie jako jednostkę w obrębie społeczności. Każde medium pociąga za sobą inny model odbioru i przyswajania treści, kolektywnego lub indywidualnego konstruowania znaczeń i włączania ich w obszar wspólnej bądź jednostkowej wiedzy o świecie. Historia rozwoju mediów może być interpretowana zatem jako historia narzędzi i technologii, które sytuowały człowieka na osi: kolektywność - indywidualność. Jedne z nich rozwijały człowieka w stronę wspólnotowości, otwierały go na współuczestników aktu komunikacyjnego i zanurzały we wspólny horyzont kulturowy. Inne zaś kierowały go w stronę samego siebie, podkreślając jego oddzielenie, osobność, inność czy wyjątkowość. Za Walterem Ongiem funkcja wspólnototwórcza może zostać przypisana słowu mówionemu, które niesie ze sobą potencjał łączenia ludzi i włączania ich we wspólny horyzont komunikacyjny, przekładający się na kolektywne i wspólnotowe doświadczenie. Jak pisze Ong:

Słowo mówione, wydobywające się z ludzkiego wnętrza, z uwagi na fizyczne właściwości dźwięku objawia sobie nawzajem istoty ludzkie jako wnętrza świadome, jako osoby; to słowo mówione tworzy z poszczególnych ludzi ściśle powiązaną grupę (Ong 1992: 108). 
Integrującej sile słowa mówionego przeciwstawiony jest oddzielający i indywidualizujący charakter słowa pisanego. Słowo, zarówno pisane, jak i drukowane, wiąże się z izolacją i, jak stwierdza Ong, zakłada „przerwanie obecności, śmierć lub możliwość śmierci adresata" (Ong 1992: 109). Z kolei Jacques Derrida określa pismo mianem „intruzji nieobecności" (Derrida 1975: 75-92), a Paul Ricoeur podkreśla wpisaną w pismo „nieobecność wspólnej sytuacji osadzonej w czasie i przestrzeni" (Ricoeur 2003: 428). Istoty owej nieobecności, braku czy oddzielenia upatrywać należy w powiązaniu pisma z przestrzenią, osadzeniu go w powierzchni zapisu, a później - zadruku. Powiązanie słowa z papierem predestynuje je do indywidualnego, jednostkowego odbioru, a co za tym idzie - zniesienia wspólnotowych więzi wynikających z kolektywnego odbioru treści, a także zmediatyzowania aktu komunikacyjnego i zapośredniczenia kontaktu pomiędzy nadawcą a odbiorcą. W momencie tworzenia tekstu nieobecny jest odbiorca, w momencie odbioru - nadawca, a w kontekście całego dzieła - nieobecny jest także sens, który potencjalnie mógłby zaistnieć między nadawcą a odbiorcą w akcie komunikacji bezpośredniej (Derrida 1975: 79).

Słowo mówione, w warunkach komunikacji bezpośredniej, ma wymiar zarówno audialny, jak i wizualny. Każde wypowiedziane słowo jest dźwiękiem, uzupełnionym o komunikaty niewerbalne, $n p$.: mimikę, grymasy twarzy czy gesty. $Z$ kolei słowo pisane jest osadzone w przestrzeni typograficznej, odnosi się tylko do płaszczyzny wizualnej. Jest czymś, co można zobaczyć - stanowi bardziej rzecz, etykietę niż zdarzenie (Ong 1992: 57). Ponadto słowo mówione niesie ze sobą potencjalność komunikacji jeden do wielu i determinuje sytuację komunikacyjną sprzyjającą tworzeniu się wspólnoty odbioru oraz wspólnoty pomiędzy nadawcą a odbiorcą. Trafnie ujmuje to Paul Levinson, określając słuchanie mianem „archetypowej formy zbiorowej percepcji" (Levinson 2006: 141). Osadzenie słowa w przestrzeni kartki, indywidualność odbioru i oddzielenie od siebie członków aktu komunikacyjnego, a także zmniejszenie performatywnego charakteru słowa, oderwanie go od konkretu, od rzeczy i przesunięcie w kierunku abstrakcji sprawiają, że zapisane słowo ukierunkowuje kulturę na jednostkę, a w obszarze znaczeniowym - konotuje nieobecność, samotność, oddzielenie, śmierć. Słowo mówione zaś, ze względu na dźwiękowy charakter, który jest jego cechą konstytutywną, powiązanie z ludzkim ciałem, z wydobywającym się z niego głosem, jest dynamiczne (Ong 1992: 55), zorientowane na życie. Jak pisze Ong:

Człowiek typograficzny przestał myśleć o słowach w kategorii wypowiadania (...) są [one] czymś martwym, choć zdolnym do dynamicznego zmartwychwstania (Ong 1992: 57).

Spoglądając na powyższe zagadnienie ze strukturalistycznego punktu widzenia, można zauważyć dychotomię: słowo mówione - słowo pisane i paralelne względem niej wartości: dynamiczność - statyczność, ożywienie - martwota, obecność - nieobecność, łączność - oddzielenie, kolektywność - samotność, wspólnotowość - indywidualność. Nakreśloną w ten sposób matrycę pojęciową zdają się uprawomocniać analizy dotyczące rozwoju mediów, powiązanych z wizualnością czy audialnością. 
Rozważania dotyczące zmian zachodzących w kulturze wskutek rozwoju mediów nie są jednak przedmiotem niniejszego artykułu, zatem przytoczonych zostanie pokrótce jedynie kilka arbitralnie wybranych przykładów. W paradygmat wspólnotowości mediów audialnych bądź audiowizualnych wpisuje się chociażby przywoływany przez Mirosława Filiciaka sposób postrzegania telefonu i gramofonu jako mediów generujących „zbiorowe doświadczenie rozszerzenia percepcji jednostek poza miejsce fizycznego pobytu" (Filiciak 2013: 188), słyszane przez mnóstwo uszu radio (Levinson 2006: 141), a także rytualny charakter kina (Altman 1987) oraz familiarny, czy nawet plemienny wymiar telewizji (Godzic 2002: 39-60). Analizując media eksploatujące wizualne reprezentacje słowa, należy wskazać na sprzyjający indywidualnej interpretacji zjawisk druk (Levinson 2006, 54-55) oraz zapośredniczające percypowanie świata doświadczenie fotografii.

\section{Wspólnotowość jako mit konstytuujący media Web 2.0}

Przytoczone pojęcia, zdające się porządkować sposób rozumienia mediów i ich wpływu na kulturę, nawet z założeniem nieostrości granic pomiędzy różnorodnymi formami medialnymi i płynności tworzonych przez nie znaczeń, nie mogą stanowić podstawy do krytycznej refleksji nad nowo-nowomedialnymi ${ }^{1}$ wariantami wspólnototwórczych platform komunikacyjnych. Według przytoczonych koncepcji należałoby postrzegać media Web 2.0, a w szczególności media społecznościowe, jako przestrzenie tworzenia się cyfrowych wspólnot. Koncepcja mediów społecznościowych jako platform wspólnototwórczych może być postrzegana jako mit, komercyjna i marketingowa narracja, snuta przez ich twórców i powtarzana przez wiernych użytkowników. Jak pisze Jan Kreft:

(...) retoryka ta opisuje media jako świat „wspólnot”, „demokracji”, „pasji współtworzenia”, „zaufania”. Sprawia, że we współczesnej świadomości Google, Yahoo czy Twitter nie są już nowomedialnymi korporacjami, czyli organizacjami medialnymi nastawionymi na osiąganie ekonomicznych celów. Stają się,"miejscami spotkań"i „,nawiązywań znajomości”, przestrzenią, w której czekają przyjaciele, miejscami nowej harmonii społecznej, agorą upodmiotowienia i materializacji ideałów zarządzania humanistycznego z jego afirmacją człowieka jako podmiotu, a nie zasobu czy członka „grupy docelowej” (Kreft 2015: 119).

Korporacyjna retoryka społecznościowości doskonale eksploatuje niejasny status słowa w sieci, co podkreślają ponadto różnorodne koncepcje związane z jego rozumieniem.

\footnotetext{
${ }^{1}$ Termin „nowe nowe media” używany jest za Paulem Levinsonem (Levinson 2008).
} 


\section{Wspólnototwórczy potencjał piśmienności w sieci}

Do uchwycenia zawieszenia słowa w sieci, pomiędzy” oralnością i piśmiennością badacze proponują rozliczne terminy. Za Ongiem przyjąć można koncepcję wtórnej oralności (Ong 1992: 182). Ongowska koncepcja przypisuje sieciowym praktykom komunikacyjnym zdolność generowania silnego poczucia wspólnoty wśród użytkowników sieci. Społecznościowy charakter mediów, powstających w uniwersum słowa wtórnie oralnego, jest zatem immanentną częścią specyfiki sieci i wynika wprost z charakteru medium. Alternatywne spojrzenie przedstawia Eugeniusz Wilk, proponując pojęcie telepiśmienności (Wilk 2000: 29), w myśl którego słowo w sieci stanowi rozszerzenie piśmienności, jest słowem pisanym o cechach słowa mówionego. Słowo w sieci umożliwia jednoczesną komunikację jeden do wielu, pozwala na wspólny odbiór zapisanych treści, na nawiązywanie łączności pomiędzy nadawcą a odbiorcą, zakłada natychmiastowość komunikacji, osadzenie jej w czasie rzeczywistym. Słowo w sieci jest ponadto chwilowe i sekwencyjne, a jednocześnie jest związane z ekranem - z cyfrową powierzchnią obrazowania. Komunikacja sieciowa jest zatem osadzona pomiędzy paradygmatem oralności a paradygmatem piśmienności. Język czy tekst internetowy konstruowany jest ponadto w oparciu o logikę rozproszenia, niespójności i nielinearności.

Sięgając do koncepcji Vilema Flusera, można stwierdzić, że członkowie „alfanumerycznego społeczeństwa", odchodząc od linearnej, historycznej logiki tekstu, zwracają się w stronę myślenia konkretem, myślenia „liczbami, formami, kolorami, dźwiękami" (Flusser 1993/1994: 45-50). Sprowadzając tezę tę do formy mniej radykalnej, można by dodać, iż użytkownicy sieci komunikują się z wykorzystaniem zbiorowych pochwał, zachwytów, zaciekawień czy niechęci. Najpowszechniejszą formą informacji zwrotnej dla komunikatu udostępnionego w mediach społecznościowych - posta na Facebooku, wpisu na Twitterze, zdjęcia na Instagramie czy Pintereście, filmu na YouTube - jest dołączenie lajka. Każdy komunikat zyskuje w ten sposób szereg emblematów, określających reakcje emocjonalne, takich jak: podniesione kciuki, uśmiechy, serduszka czy niezadowolone miny. Spontaniczny i natychmiastowy komentarz, będący reakcją na określony komunikat, jest $w$ istocie oparty na mechanizmie reakcji grupowej, bazującej na emocjach. Kolejnym aspektem wpływającym na wspólnototwórczy charakter słowa w sieci jest wielokanałowość komunikacji sieciowej. Komunikacja Web 2.0 wykracza jednak zdecydowanie poza słowo (za)pisane i ma charakter multimodalny. W obręb komunikacji w mediach społecznościowych, poza pojedynczym postem czy opublikowanym obrazem bądź filmem, zaliczyć należy także takie formy, jak: konwersacje indywidualne bądź zbiorowe (np. przez aplikację Messenger czy WhatsApp), grupy dyskusyjne, wideotransmisje na żywo czy webinaria. Każda z tych form przybliża komunikację sieciową do wspólnotowej komunikacji oralnej, eksponując takie jej aspekty, jak natychmiastowość, możliwość reakcji, odpowiedzi w czasie rzeczywistym, zaangażowanie wielu zmysłów, nie tylko wzroku, lecz także - coraz powszechniej - 
słuchu i dotyku. Wszystkie te aspekty predysponują komunikację sieciową do stawania się katalizatorem cyberspołeczności i zwiększają jej wspólnototwórczy charakter.

\section{Świat usieciowionej komunikacji jako uniwersum alienacji}

W opozycji do przytoczonych powyżej argumentów, potwierdzających fakt, że wspólnotowość komunikacji w sieci oparta jest $w$ istocie na charakterze samego medium, należy przyznać, iż relewantnym aspektem cyfrowego doświadczenia współczesnego człowieka jest przekonanie o tym, że

jedyna forma kulturowa, która jest w stanie wyrosnąć na podglebiu internetowych praktyk komunikacyjnych to kultura alienacji i nieobecności, w której relacje podmiotowe zastąpiono stosunkiem podmiot-przedmiot (Górska-Olesińska 2009: 29).

Oddzielenie, symulacyjny charakter bycia w cyberprzestrzeni, zapośredniczenie doświadczenia w nowomedialnych doświadczeniach użytkowników sieci determinuje i wzmacnia paradygmat indywidualności, jednostkowości i spersonalizowania osoby w sieci. Skuteczność szeroko opisywanych przez Krefta marketingowych praktyk perswazyjnych, eksploatujących ideę wspólnoty i milcząco transformujących ją W "grupę docelową" (Kreft 2015: 103-125), wzmacniana jest dzięki żyznemu gruntowi społecznemu, na który pada. Obietnica uczestnictwa w opartej na zaufaniu grupie przyjaciół, szansa tworzenia cyberwspólnoty jest dokładnie tym, czego pragnie baumanowski, ponowoczesny, osamotniony człowiek (Bauman 1996: 73-84). Determinowane przez interakcję z nowymi nowymi mediami mechanizmy uzewnętrzniania procesów kognitywnych, eksternalizacji kojarzenia, formułowania zagadnień, stawiania pytań (Manovich 2006; De Kerckhove 1996) nie pozostają bez wpływu na charakter związków społecznych. Przeniesienie wspólnoty do cyberprzestrzeni skutkuje przeniesieniem jej poza obszar jednostkowego doświadczenia i - tak jak w przypadku wskazanych powyżej ludzkich procesów myślowych - eksternalizuje doświadczenie wspólnotowe.

\section{Perswazyjne narracje o wspólnotowości mediów Web 2.0}

Opisane zależności pomiędzy mediami społecznościowymi a koncepcją wspólnotowości oraz status słowa w sieci składają się na pierwszy fundament mitu sieci Web 2.0 jako przestrzeni wspólnototwórczej. Drugim fundamentem jest interpretowanie ich w kontekście wywiedzionej od Marcela Mausse'a teorii daru (Mauss 1973). Na powiązanie ze wspomnianymi koncepcjami powoływał się m.in. twórca Facebooka Mark Zuckenberg, który, jaki pisze David Kirckpartick: „był bardzo oddany idei Facebooka jako narzędzia społecznego, aż do granic naiwności" (Kirckpatrick 2011: 161), przyrównując aktywność w mediach społecznościowych do rytualnej wymiany darów. Przedmiotem owej wymiany miało być zainteresowanie, zaangażowanie, obdarowywanie 
uwagą. Podobne idee przyświecały twórcom wyszukiwarki Google, którzy przez lata głosili maksymę „don't be evil", przekonując, że ich nadrzędną misją jest „uporządkowanie światowych zasobów informacji i uczynienie świata lepszym". Społecznościowe motywacje twórców internetowych gigantów - przynajmniej na poziomie deklaratywnym - znajdują odzwierciedlenie w mechanizmach działania algorytmów selekcjonujących treści. Poza społecznościowymi predyspozycjami określonych mediów i sposobów komunikacji, poza deklaracjami twórców i reakcjami użytkowników, u podstaw społecznościowych mitów nowych nowych mediów leży właśnie ich algorytmizacja. Twórcy algorytmów Google, Facebooka czy Instagrama deklarują, że są one oparte na logice wyszukiwania społecznościowego. W myśl koncepcji wyszukiwania społecznościowego, które obszernie charakteryzuje Alexander Halavais, internetowe wyszukiwarki opierają się na "gromadzeniu ukrytego ludzkiego osądu dotyczącego treści sieci i wartości poszczególnych stron" (Halavais 2012, 196). Według tych założeń najwyżej publikowane strony czy pojawiające się w górnej części news feedów posty cieszą się największym zainteresowaniem użytkowników oraz są najczęściej cytowane i linkowane. Społecznościową retorykę wyszukiwania w Google uzupełniają także takie funkcjonalności, jak: podobne wyszukiwania bądź dostępna w anglojęzycznej wersji wyszukiwarki funkcja „People Also Ask". W istocie jednak widoczność w każdym z mediów wiąże się z całym szeregiem zróżnicowanych (choć jedynie domniemanych czynników) - począwszy od odpowiednich parametrów technicznych, znaczników, elementów kodu czy tagów, poprzez profile linków i udostępnień, aktualność publikowanych treści, a zatem godzin czy dni, w których są udostępniane, aż po oznaczenie treści odpowiednimi słowami kluczowymi. Każdy z tych czynników z wykorzystaniem profesjonalnych narzędzi analitycznych można przystosować do wymogów algorytmu, sprawiając tym samym, że najpopularniejsza treść nie będzie wcale treścią w istocie najczęściej czytaną czy oglądaną, a jedynie wspartą największymi funduszami, przeznaczonymi na odpowiednie narzędzia czy pracę specjalistów.

Powyższe rozpoznania obnażają fasadowość koncepcji kolektywnej selekcji, wspólnotowego tworzenia treści i równych szans dla internetowych twórców i mogą prowadzić do nowego wniosku, dotyczącego charakteru komunikacji czy słowa w Internecie. Znaczenie w sieci zyskują nie tyle zdjęcia, teksty czy wideo, które wzbudzają zainteresowanie, zaangażowanie bądź zachwyt użytkowników, lecz te, do których przyporządkowano odpowiednie metaznaczniki. Pomimo powszechności paradygmatu audiowizualności w sieci, wbrew powszechnemu przekonaniu o dominacji ikonosfery, to warstwa "meta" internetowych treści, na którą składają się znaczniki w kodzie programistycznym, mają znaczący wpływ na widoczność w sieci. Internetowe treści mogą mieć charakter audialny bądź wizualny, oralny bądź piśmienny, jednak u podstaw wszystkich kodów komunikacji sieciowej leży kod programistyczny. Paradygmat interaktywności, społecznościowego wyszukiwania, propozycja postrzegania użytkowników sieci w odniesieniu do koncepcji produsera (Kreft 2015: 60), będącego producentem i użytkownikiem, twórcą i odbiorcą treści, jest w istocie niepełna. Ponad podziały na internautów aktywnych i pasywnych, twórców i odbiorców nadpisać należy przede 
wszystkim nieuświadomiony, ukryty i nieoczywisty podział na biernych, zanurzonych w audiowizualnym świecie kultury uczestnictwa internautów, przyjmujących generowane dla nich treści, karmionych mitem społecznościowego wyszukiwania, zaangażowania i obdarowywania się atencją, oraz posługujących się kodami programistycznymi projektantów interfejsów, twórców algorytmów bądź autorów treści do nich dostosowanych, posługujących się językami programowania, matematycznymi algorytmami i niejawnymi rozwiązaniami technologicznymi. Ukrycie mechanizmów działania technologii, publikujących i selekcjonujących treści, sprawia, że usieciowiona komunikacja zaczyna funkcjonować jak ideologia, której jednym z głównych wyznaczników jest przecież nieujawnianie własnego istnienia (Marjankowska, Drygalska 2016). W świetle powyższych wniosków wspólnotowość, promowaną jako dominującą zasadę organizującą funkcjonowanie użytkownika w sieci, rozpatrywać można jako ideologiczny konstrukt. Narracja o wspólnotowości mediów Web 2.0 przywiązuje odbiorców do mediów, buduje zaufanie, skłania do dzielenia się informacjami o sobie, bazując na poczuciu izolacji i osamotnienia, oferując w zamian jedynie iluzję przynależności i doświadczenia kolektywności.

\section{Bibliografia}

Altman Ch., 1987, W stronę teorii gatunku filmowego , Kino”, nr 6.

Bauman Z., 1996, Etyka ponowoczesna, Warszawa: Wydawnictwo Naukowe PWN.

Castells M., 2013, Sieci oburzenia i nadziei, Warszawa: Wydawnictwo Naukowe PWN.

De Kerckhove D., 1996, Powłoka kultury: odkrywanie nowej elektronicznej rzeczywistości, Warszawa: Mikom.

Derrida J., 1975, Pismo i telekomunikacja [w:] „Teksty: teoria literatury, krytyka, interpretacja”, nr 3 (21).

Filiciak M., 2013, Media wersja beta. Film i telewizja w czasach gier komputerowych i internetu, Gdańsk: Wydawnictwo Naukowe Katedra.

Flusser V., 1993/1994, Społeczeństwo alfanumeryczne, ,Lettere Internationale", nr 1.

Godzic W., 2002, Telewizja jako kultura, Kraków: Rabid.

Halavais A., 2012, Wyszukiwarki internetowe a społeczeństwo, Warszawa: Wydawnictwo Naukowe PWN.

Kirckpatrick D., 2011, Efekt facebooka, Warszawa: Wolters Kluwer Polska.

Kreft J., 2015, Za fasadq społeczności, Kraków: Wydawnictwo Uniwersytetu Jagiellońskiego.

Levinson P., 2008, Nowe nowe media, Kraków: WAM.

Levinson P., 2006, Miękkie ostrze czyli historia i przyszłość rewolucji informacyjnej, Warszawa: Muza.

Manovich L., 2006, Język nowych mediów, Warszawa: Łośgraf.

Marjankowska A., Drygalska E., 2016, Software studies - co to takiego?, „Znak", nr 737, http://www. miesiecznik.znak.com.pl/software-studies-co-to-takiego.

Mauss M., 1973, Szkic o darze. Formy i podstawa wymiany w społeczeństwach archaicznych [w:] Socjologia i antropologia, Warszawa: PWN.

Ong W., 1992, Oralność i piśmienność. Słowo poddane technologii, Lublin: Wydawnictwo Katolickiego Uniwersytetu Lubelskiego. 
Ricouer R., 2003, Mowa i pismo [w:] Antropologia słowa zagadnienia i wybór tekstów, red. G. Godlewski, A. Mencwel, R. Sulima, Warszawa: Wydawnictwo Uniwersytetu Warszawskiego.

Szpunar M., 2010, Nowe media a paradygmat kultury uczestnictwa [w:] M. Graszewicz i J. Jastrzębski (red.), Teorie komunikacji i mediów 2, Wrocław: Wrocławskie Wydawnictwo Oświatowe.

Wilk E., 2000, Nawigacja słowa. Strategie werbalne w przekazach audiowizualnych, Kraków: Rabid. 